\title{
Behavioral Finance of Impact Investing The Case of Donor-Advised Funds
}

By: Eric Hangen, Michael Swack, and Jordan Hensley

April 14, 2020

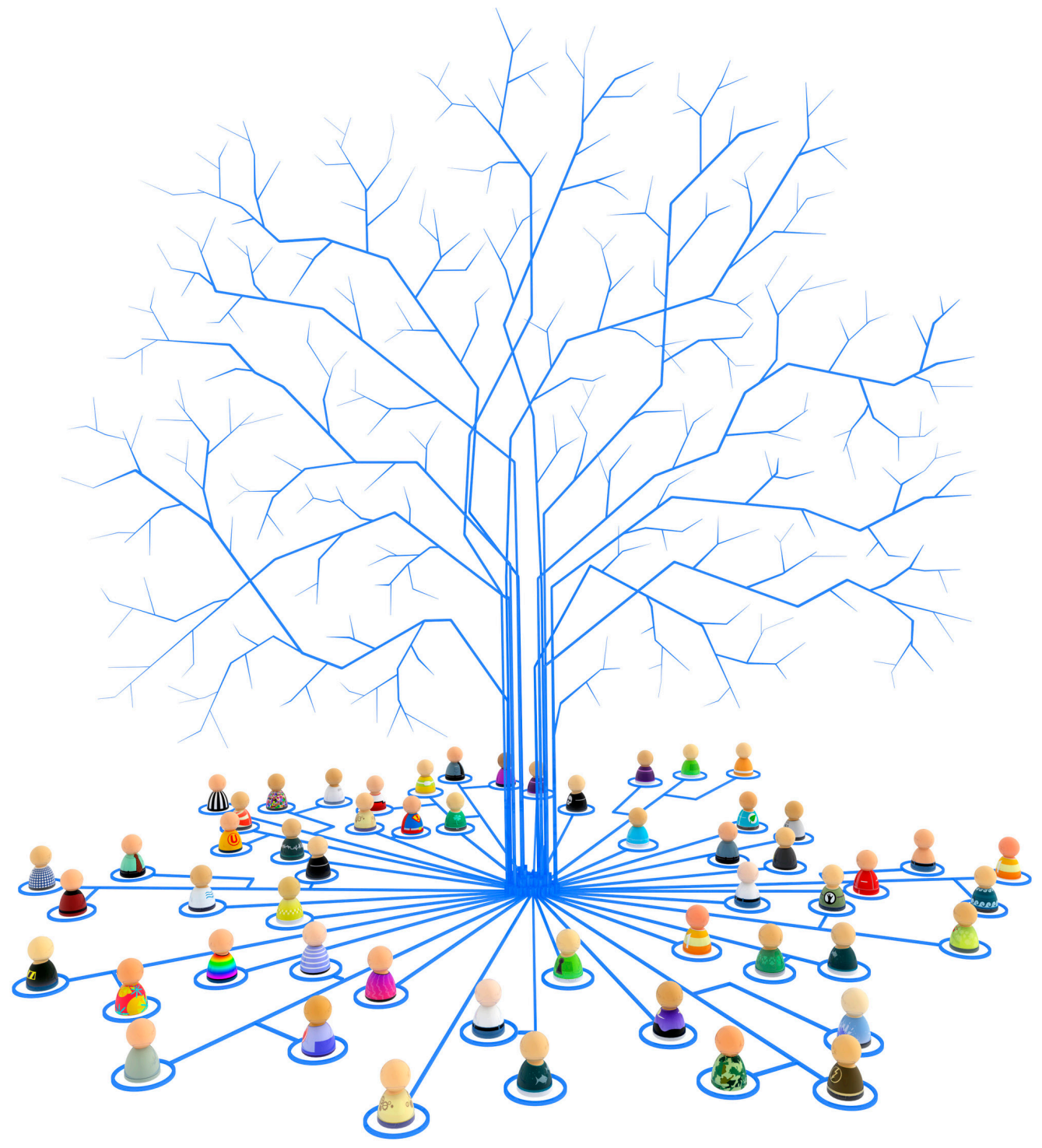

This paper is a publication of the Center for Impact Finance at the Carsey School of Public Policy. 


\section{Summary / Abstract}

Undeployed charitable assets in donor-advised funds (DAFs) reached $\$ 121.4$ billion in 2018-including $\$ 33.9$ billion at Community Foundations. Most of these undeployed funds are invested in conventional financial instruments. However, DAFs present a unique opportunity to promote impact investing into the local community, including Community Development Financial Institutions (CDFIs) that serve their local communities. In addition to having already expressed a clear interest in using funds for social purposes, DAF donors could potentially realize a double-bottom-line benefit by placing undeployed funds in impact investments rather than traditional stocks or bonds. Community impact investing should be an appealing option for DAF donors at Community Foundations. The donor has already relinquished any possibility of personal benefit from the funds in their DAF, and should therefore be interested exclusively in maximizing the social impact they can generate with their funds. Lending the money to a social interest project or organization for a few years while the donor decides where to grant the funds seems like a rational strategy to achieve greater impact. A substantial body of evidence from the field of behavioral economics suggests that most people do not, however, make rational decisions about their investments or finances. Instead, a variety of cognitive biases tend to drive their decisions, often resulting in sub-optimal financial outcomes.

In this study, DAF donors were invited to complete a survey by the local community foundation that held their investment. In the survey, the donors were asked to imagine that they had just contributed a sum of money to their donor-advised fund. The survey then asked the donors to determine how they wanted to invest their funds before they were granted out to charitable organizations. Donors were given four options, allocating between them a percentage of their funds. Donors could then select the desired term and interest rate for their investment in the local community impact fund. The results suggest that Community Foundations can exert considerable influence over donor allocations to community impact investing funds simply by changing how they frame the request. In particular, if Foundations are willing to recommend a default allocation to community impact investmentseven while allowing the donor full choice over the final allocation that is actually implemented-they will see substantially more funds going to this use.

\section{Background}

The National Philanthropic Trust estimates that undeployed charitable assets in donor-advised funds (DAFs) reached $\$ 121.4$ billion in 2018-including $\$ 33.9$ billion at Community Foundations. ${ }^{1}$ It is believed that most of these undeployed funds are invested in conventional financial instruments. But DAFs present a unique opportunity to promote impact investing. In addition to having already expressed a clear interest in using funds for social purposes, DAF donors could potentially realize a double-bottom-line benefit by placing undeployed funds in impact investments rather than traditional stocks or bonds. With DAF annual payout rates sitting at 20 percent, a dollar in a DAF has an expected life of 5 years during which it could be invested for community good before being donated to a charitable organization. Yet only a small fraction of DAF donors have made any impact investments despite significant efforts on the part of many DAF sponsors to offer impact investing opportunities. Donor-advised fund sponsors, including community foundations, have also expressed concerns over the time and expense that it requires to educate and advise DAF donors about impact investing. ${ }^{2}$

On its face, impact investing should be an appealing option for DAF donors. The donor has already relinquished any possibility of personal benefit from the funds in their DAF, and should therefore be interested exclusively in maximizing the social impact they can generate with their funds. Lending the money to a local project or intermediary, such as a Community Development Financial Institution (CDFI), for a few years while the donor decides where to grant the funds seems to us like a rational strategy to achieve greater impact. As one donor put it to us, "What really matters to me is that our funds actually help make things better in our community." Another donor agreed, saying "I feel strongly that funds intended to be given away should do good while sitting in an advised fund before they are given away. [Funds] should be invested 100\% for impact." Furthermore, depending on the interests of the donor, investing undeployed funds on the stock market might actually run counter to their impact goals. As another donor expressed to us, "I don't want to be donating to, say, public health and environmental causes while investing in Philip Morris and Exxon." 
To be sure, there are arguments to be made against impact investing. Some DAF donors feel that there exists an "obligation to the [eventual grant] recipients to keep up with market performance at the lowest risk," as one put it. In a similar vein, another donor argued, "One of my reasons for having a donor advised fund is to put the money into professionally managed accounts that would likely yield a higher return than I could on my own, thereby increasing my ability to impact the community." Other donors might be skeptical about whether an impact investment will generate the promised investment. Or, they might have a philosophical opposition to activities to be funded by the investment ("I have found impact investing to be associated with certain left-wing ideologies," declared one presumably conservative donor). Possibly, the majority of DAF holders have made a careful, informed decision not to place funds in impact investments, based on one or more of these lines of argument.

On the other hand, it is also possible that many donors simply have not fully thought through their choices, and are even underinvesting in impact investments relative to what they might choose upon more thorough reflection. Consider these statements that we heard from donors when asking them about how they would like to allocate their DAF funds:

- "I don't have a desire to control the investment strategy. (In fact, the opposite: I don't want to have to think about it.)"

- "I'm not knowledgeable enough to make an informed decision and I haven't thought about what my investment objectives should be."

A substantial body of evidence from the field of behavioral economics suggests that most people do not, in fact, make rational decisions about their investments or finances. ${ }^{3}$ Instead, a variety of cognitive biases tend to drive their decisions, ${ }^{4}$ including the inertial effects we see in our study. ${ }^{5}$ These cognitive biases can result in sub-optimal financial outcomes relative to people's expressed preferences. Bhamra and Uppal (2019) find that investors tend to suffer from "familiarity biases," investing in a few assets with which they are more familiar, with the result that they hold under-diversified portfolios. ${ }^{6}$ Beshears et al. (2007) find that simply changing the default option for worker participation in their retirement program (to automatic enrollment where the worker can opt out) dramatically changes participation rates. ${ }^{7}$ Even investment professionals suffer from cognitive biases. For example, Cen et al. (2019) find that financial analysts are impacted by anchoring biases (a sort of cognitive over-dependence on an initial piece of information) in assessing the future profitability of firms. ${ }^{8}$

There is also a body of work in the philanthropic space that shows how behavioral nudges and cognitive strategies influence charitable giving. Kamdar et al. (2015) find that the way charitable organizations frame their requests can have a substantial impact on giving. ${ }^{9}$ These "nudges" can vary based on the goals of the charitable organization, and not all methods are likely to work in all circumstances. ${ }^{10}$ Regardless, charitable giving is an economic activity, and there is every reason to believe that DAF donors are subject to the same cognitive biases as other economic decision makers. ${ }^{11}$ Up to this point, however, very little research has been done on this topic. As a result, DAF sponsors are currently operating without an understanding of how behavioral finance may influence the potential demand for impact investing and to effectively market impact investing opportunities.

\section{Study Design}

We designed a simple experiment to see whether DAF donors' choices of how to invest undeployed funds can be influenced by behavioral "nudges." 12 For the purpose of this study, we define a "nudge" as a change in how donor choices are presented, with the intention of increasing the percentage of undeployed funds that donors designate for community impact investments. Importantly, these nudges do not restrict choice for the donors (they can choose any allocation of funds to community impact investments, including zero), nor do they change the underlying incentives to invest (there are no special rewards provided for donors allocating funds for impact investing).

The experiment worked as follows: DAF donors were invited to complete a survey by the local Community Foundation that held their investment. In the survey, the donors were asked to imagine that they had just contributed a sum of money to their donor-advised fund. The survey then asked the donors to determine how they wanted to invest their funds before they were 
granted out to charitable organizations. Donors could select among four options, allocating a percentage of their funds between the following options:

- A conventional, actively managed portfolio with broad exposure to global equity and fixed-income markets

- A mix of low-cost, passively managed stock and bond index funds

- A "socially responsible" portfolio invested in a mix of stock and bond funds that utilize environmental, social and governance factors in the security selection process, and/or actively engage with companies to promote social responsibility among companies in which the fund invests.

- A "Local Community Impact Fund" described to donors as a fund investing "in a range of nonprofit and social purpose organizations that serve the community where you live."

Donors could then select the desired term and interest rate for their investment in the local community impact fund.

Without their knowledge, donors responding to the survey were randomly selected to be placed into one of four different groups. Each group received a slightly different presentation of the Local Community Impact Fund investing option:

- The baseline group received the following additional explanation about the Local Community Impact Fund: "These investments may help to grow businesses in low-income communities, develop health care centers and grocery stores in areas that lack them, build affordable housing, or help low-income families to build or repair a home, buy a car to get to work, or pay for education. This fund is intended to return capital over time with only modest financial gain."

- The second group received a more emotional appeal utilizing stories about recipients of investments made by the Local Community Impact Fund-for example, about a single mother working as a home health care aide who would benefit from the construction of new affordable housing that she could rent. We will refer to this framing of investment choices as the "storytelling approach."
- The third group received the same description of the options as the baseline group. However, the survey had a set of numbers already entered in the table where respondents chose how to allocate their investments. Specifically, 40 percent of investments were selected to go to the Local Community Impact Fund, and 20 percent to each of the other options. Respondents were able to edit percentages to whatever allocation they preferred. The survey text above the table read, "We have recommended an allocation for your consideration that we believe balances the need for local investment by the foundation and its donors with the need to generate sufficient returns to maintain future grant distributions over one's lifetime, but you may edit the percentages as you wish." This option could thus be described as anchoring the respondent to the initial value of 40 percent assigned to the Local Community Impact Fund-and as putting the weight of a recommendation from their local community foundation behind that initial value. We will refer to this framing of investment choices as the "recommended allocation" approach.

- Finally, the fourth group received the same description of the options as the baseline group, with one piece of additional information about the Local Community Impact Fund: "Community impact investing is a growing trend in the United States and increasingly, many high-net-worth individuals, family offices, and leading foundations are dedicating a significant portion of their assets to place-based community investing." We will refer to this framing of investment choices as the "norming" approach (sharing information to establish impact investing as a social norm).

Two community foundations - the Seattle Community Foundation and the Grand Rapids (Michigan) Community Foundation-agreed to participate in the study and sent a neutrally-worded invitation to the survey to their donors during the fall of 2019. We received 195 total survey responses, 141 from Seattle and 54 from Grand Rapids.

Respondents were roughly evenly distributed across the 4 different versions of the survey- 49 for the baseline approach, 43 for the storytelling approach, 54 for the recommended allocation approach, and 49 for the norming approach. 
A major limitation of the study is that survey respondents were being asked hypothetical questions about an investment allocation - not to actually choose an investment allocation of real dollars.

\section{Study Results}

On average, respondents in the baseline survey group chose to allocate 18.5 percent of their investments to the Local Community Impact Investment Fund. This result is interesting in and of itself, as it suggests a level of interest in community impact investing that is greater than what has been achieved to date.

We observe powerful impacts on donor allocations to the Local Community Impact Investment Fund for the "recommended allocation" approach. Simply by making a suggestion to respondents-a suggestion that respondents could readily opt out of, and with nothing more than a mildly-worded recommendation to back it up, this approach generated a 59 percent increase in the funds allocated to the Local Community Impact Investment Fund, compared to the baseline. The result was highly statistically significant $(\mathrm{t}=2.86, \mathrm{p}<.01$ for a two-tailed test).

We also observe a modest bump in allocations to the Local Community Impact Investment Fund for the other two "nudges"- the storytelling approach and the norming approach-but in these cases, the results are not statistically significant.

\section{TABLE 1. SUMMARY OF COMMUNITY IMPACT INVEST- MENT ALLOCATION DECISIONS BY SURVEY GROUP}

\begin{tabular}{|l|c|c|c|}
\hline Survey Group & $\begin{array}{c}\text { Mean allocation } \\
\text { to Community } \\
\text { Impact Fund }\end{array}$ & $\begin{array}{c}\text { T score for } \\
\text { comparison } \\
\text { to baseline } \\
\text { group }\end{array}$ & $\begin{array}{c}\text { P value for } \\
\text { comparison to } \\
\text { baseline group } \\
\text { (2-tailed) }\end{array}$ \\
\hline Baseline & $18.5 \%$ & N/A & N/A \\
\hline $\begin{array}{l}\text { Storytelling } \\
\text { approach }\end{array}$ & $19.9 \%$ & 0.29 & 0.77 \\
\hline $\begin{array}{l}\text { Recommended } \\
\text { allocation } \\
\text { approach }\end{array}$ & $29.4 \%$ & 2.86 & 0.005 \\
\hline $\begin{array}{l}\text { Norming } \\
\text { approach }\end{array}$ & $19.8 \%$ & 0.26 & 0.79 \\
\hline
\end{tabular}

We find that donor demographics are significant predictors of the amounts they will allocate to impact investing. Donors who are female, younger, and who have smaller amounts in their DAFs all tend to allocate larger amounts to impact investing, as seen in Table 2 .

\section{TABLE 2. DEMOGRAPHIC DIFFERENCES}

\begin{tabular}{|l|l|c|c|}
\hline $\begin{array}{l}\text { Demographic } \\
\text { comparison }\end{array}$ & $\begin{array}{l}\text { Mean allocation to } \\
\text { Community Impact } \\
\text { Fund }\end{array}$ & $\begin{array}{c}\text { T score for } \\
\text { comparison }\end{array}$ & $\begin{array}{c}\text { P value for } \\
\text { comparison } \\
\text { (2-tailed) }\end{array}$ \\
\hline Men vs. women & $\begin{array}{l}16.9 \% \text { for men; } \\
29.1 \% \text { for women }\end{array}$ & 3.25 & 0.001 \\
\hline $\begin{array}{l}\text { Donors 65 and } \\
\text { older vs. donors } \\
\text { younger than } 65\end{array}$ & $\begin{array}{l}17.2 \% \text { for seniors; } \\
27.0 \% \text { for donors } \\
\text { under 65 }\end{array}$ & 2.70 & 0.008 \\
\hline $\begin{array}{l}\text { Donors with under } \\
\$ 500,000 \text { in DAF } \\
\begin{array}{l}\text { vs. donors with } \\
\$ 500,000 \text { or more }\end{array}\end{array}$ & $\begin{array}{l}14.9 \% \text { for large } \\
\text { donors; } 24.8 \% \text { for } \\
\text { small donors }\end{array}$ & 2.68 & 0.008 \\
\hline
\end{tabular}

To control for possible effects of demographic differences between survey groups, we run an OLS regression to compare the baseline and recommended allocation approaches, including control variables for the gender, age, and DAF holdings of the respondents. Due to small sample sizes we reduce the age and DAF holdings variables to dichotomous variables (donor is under 65 or 65 or older; donor has less than $\$ 500,000$ in the $\mathrm{DAF}$ or over $\$ 500,000)$. We find that all variables save gender continue to be statistically significant, and the magnitude of the effect of the recommended allocation approach remains the same after controlling for these donor characteristics. Regression output is presented in Table 3- "Anchoring" refers to whether the respondent received the "Recommended Allocation" language. 
TABLE 3. REGRESSION OUTPUT

\begin{tabular}{|c|c|c|c|c|c|c|}
\hline Source & SS & $d f$ & MS & Number of obs & $=$ & 74 \\
\hline Model & 8707.42243 & 4 & 2176.85561 & Prob $>F$ & $=$ & 0.0002 \\
\hline Residual & 23327.7127 & 69 & 338.082793 & R-squared & $=$ & 0.2718 \\
\hline & & & & Adj R-squared & $=$ & 0.2296 \\
\hline Total & 32035.1351 & 73 & 438.837468 & Root MSE & $=$ & 18.387 \\
\hline
\end{tabular}

\begin{tabular}{r|rrrrrr}
\hline LocalCommu d & Coef. & Std. Err. & $t$ & $P>|t|$ & [95\% Conf. Interval] \\
\hline Anchoring & 10.40391 & 4.299048 & 2.42 & 0.018 & 1.827546 & 18.98028 \\
Senior & -9.365702 & 4.568325 & -2.05 & 0.044 & -18.47926 & -.2521425 \\
genderflagn & -5.537836 & 4.518266 & -1.23 & 0.224 & -14.55153 & 3.475858 \\
Fund500kn & -16.11155 & 4.452409 & -3.62 & 0.001 & -24.99386 & -7.229235 \\
_cons & 32.83857 & 4.661174 & 7.05 & 0.000 & 23.53979 & 42.13736 \\
\hline
\end{tabular}

Variables:

- Dependent variable is the percentage of DAF funds allocated to a Local Community Impact Investment Fund

- Anchoring: = 1 if respondent received recommendation for community impact investment allocation; = 0 if respondent was in baseline group

- Senior: = 1 if respondent was 65 or older, 0 otherwise

- Genderflag: = 1 if respondent was male, 0 if female

- Fund500k: = 1 if respondent's DAF had $\$ 500,000$ or more in assets, 0 otherwise

\section{Conclusion}

The results suggest that Community Foundations can exert considerable influence over donor allocations to community impact investing funds. In particular, if the Foundations are willing to simply recommend a default allocation to community impact investments-even while allowing the donor full choice over the final allocation that is actually implemented-they will see substantially more funds going to this use.

We anticipate that investment advisors at DAF sponsor organizations might resist such an approach, with two particular sources of reluctance. First, the investment advisors might argue that principles of good financial stewardship require that DAF funds should be invested for maximum financial return, regardless of impact. We would argue in response that these investment advisors themselves might be suffering from what behavioral economists would call a "status quo" cognitive bias-in the investment world, most funds are typically invested in conventional stock and bond funds, with an eye only to financial risk and return. But just because funds for other goals (such as retirement) are managed in this way, should the same thinking really apply to funds for which the donor has already explicitly prioritized their social impact?

Second, the investment advisors might object to the use of behavioral "nudges" to influence donor behavior, either claiming that "donors know best" or that it would be unseemly for a DAF sponsor to attempt to influence their choices. This general class of objection is frequently encountered in behavioral economics and is addressed by Thaler and Sunstein (2003) ${ }^{13}$ First, the assumption that DAF holders are making rational, informed decisions about their investments that best meet the goals they have set for their funds and need no help to make better decisions is questionable at best, given the behavioral finance literature. Second, a decision not to make any recommendation on how to invest undeployed DAF funds still represents an active decision on the part of the DAF sponsor, with known consequences for how funds will be invested. It is therefore incumbent upon the DAF sponsor to reflect carefully on what it truly believes is the socially optimal allocation of funds. Finally, it is important to recognize that strategies such as recommending an allocation of funds for impact investing do not in any way coerce the donor into a decision. The donor is still free to decide how to allocate their funds-the difference is only in what the default option looks like. Again, given the fact that DAF funds have been explicitly designated for social impact, it is hard to reconcile such a goal with a default investment allocation to conventional stocks and bonds. 


\section{Endnotes}

1. National Philanthropic Trust (2019). The 2019 DAF Report. Online at: https://www.nptrust.org/reports/daf-report/

2. There are also legal considerations. See Levitt, David (2014). "Impact Investing Through a Donor-Advised Fund." Adler \& Colvin. https://www.adlercolvin.com/wp-content/ uploads/2017/12/Impact-Investing-Through-a-DonorAdvised-Fund.pdf

3. See, for example: Tim Richards (2014). Investing Psychology: The Effects of Behavioral Finance on Investment Choice and Bias. Hoboken, New Jersey: John Wiley \& Sons, Inc.; Michael Pompian (2006). Behavioral Finance and Wealth Management. Journal of Financial Economics, 2011, Vol. 102(1): 1-27.

4 Ritter, J. R. (2003). Behavioral finance. Pacific-Basin Finance Journal, 11(4), 429-437.

5. Burton, E., and Shah, S. (2013). Behavioral Finance (1st edition). Wiley.

6. H. Bhamra and R. Uppal (2019). "Does Household Finance Matter? Small Financial Errors with Large Social Costs." American Economic Review 2019, Vol. 109(3): 1116-1154.

7. Beshears, Choi, Laibson, and Madrian (2006). “The Importance of Default Options for Retirement Savings Outcomes: Evidence from the United States." National Bureau of Economic Research Working Paper 12009. https://www.nber.org/papers/w12009.pdf

8. Ling Cen, Gilles Hilary, and K.C. John Wei, “The Role of Anchoring Bias in the Equity Market: Evidence from Analysts' Earnings Forecasts and Stock Returns." Journal of Financial and Quantitative Analysis, 2013, Vol. 48(1): 47-76.

9. Kamdar, A., Levitt, S. D., List, J. A., Mullaney, B., and Syverson, C. (2015). "Once and Done: Leveraging Behavioral Economics to Increase Charitable Contributions." In SPI Working Paper.

10. See Karlan, Tantia, and Welch (2019). "Behavioral Economics and Donor Nudges: Impulse or Deliberation?” Stanford Social Innovation Review. Retrieved from https:// ssir.org/articles/entry/behavioral_economics_and_donor_ nudges_impulse_or_deliberation

11. Andreoni, J. (2015). "Warm Glow and Donor-Advised Funds: Insights from Behavioral Economics." Boston College of Law Conference Papers. Retrieved from http://lawdigitalcommons.bc.edu/philanthropyforum/ donoradvised2015/papers/4/

12. See Richard Thaler and Cass Sunstein (2008). Nudge: Improving Decisions about Health, Wealth, and Happiness. New Haven: Yale University Press.

13. Richard Thaler and Cass Sunstein (2003). "Libertarian Paternalism." American Economic Review, Vol. 93, No. 2: $175-179$. 


\section{TI University of New Hampshire Carsey School of Public Policy}

The Carsey School of Public Policy at the University of New Hampshire is nationally recognized for its research, policy education, and civic engagement. The school takes on pressing public issues with unbiased, accessible, and rigorous research; builds the policy and political problem-solving skills of its students; and brings people together for thoughtful dialogue and practical problem-solving.

Huddleston Hall • 73 Main Street • Durham, NH 03824

(603) 862-2821 TTY UsERS: DIAL 7-1-1

OR 1-800-735-2964 (RELAY N.H.)

carsey.unh.edu 